\title{
Will High School Projects Help to Choose a Way to Science for Students?
}

\author{
Oleg V. Koliasnikov, Ekaterina A. Mendeleeva, Natalia I. Morozova, Marina G. Sergeeva, \\ Alexander S. Sigeev \\ A.N. Kolmogorov Advanced Educational Scientific Center \\ M.V. Lomonosov Moscow State University \\ Moscow, Russia
}

\begin{abstract}
Project-based approach is the way to overcome the gap between school education and modern science. This pathway allows students to be a part of modern scientific research and obtain valuable results. The best efficiency would lead to full collaboration between school and research centers.
\end{abstract}

\section{Introduction}

The number of students in math, physics, chemistry and life sciences has steadily decreased over the last decades [1]. It is typical both for Russia and for most of developed countries. It is probably caused by the education gap between common school and modern science, increasing due to high progress in science, especially in physical and life sciences. Magnet (or specialist) schools can decrease the distance between science and school education a little, but not completely, because the education and science speak drastically different languages. School gives knowledge that already exists, whereas science deals with the generation of new knowledge. So we need an additional way that will let us teach not only chemistry or math but science paradigm in whole. One of such ways is project-based approach.

\section{Project-based approach in AESC MSU}

Kolmogorov Advanced Educational Scientific Center [2], so-called Kolmogorov School or AESC, one of M.V. Lomonosov Moscow State University departments, was founded by Acad. A.N. Kolmogorov in 1963. The mission of AESC is to gather gifted pre-University students (14-16 years old) from all-Russia to teach them at University style in order to simplify their start to science. Most of our students continue education at university level, so the problem of scientific education is of immediate interest.

In 2003 in AESC was started a new class focusing on the life sciences. This class was initiated by Faculty of Bioengineering and Bioinformatics (FBB) of MSU and project-based approach was implemented in the education program of class.
Thereafter, all students make simple investigations managed as a project. At the beginning, it was short unusual synthetic or analytical research in any field of chemistry. Many teachers in AESC as researchers or professors are able to give students problems for investigations but school facilities are not sufficient for serious work. That's why we tried to collaborate with researchers of Moscow State University and leading scientific centers such as A.N. Nesmeyanov Institute of Organoelement Compounds, L.Ya. Karpov Institute of Physical Chemistry, A.V. Topchiev Institute of Petrochemical Synthesis and others. Now AESC becames the unique Russian secondary school where students have an opportunity to work in research laboratories on actual scientific problems. Their investigation projects are sometimes performed directly on the cutting edge of modern science.

Since 2003 more than 130 projects have been completed and more than 30 are in progress now. Students complete their projects in spring and present results at annual AESC conference. About 40 of them were presented at the student local and international conferences and science fairs and received high marks from experts. During last years our students regularly present their projects on MILSET Expo Science International. Results of more than 25 projects were reported on scientific conferences. About ten articles were published in peer-reviewed journals. It highly motivates students to taking part in investigation projects.

However, there are a lot of problems in organization of project-based approach.

For example, we estimated the chemistry educational background of our students using problems of UK A-level exams. We revealed that they have good theoretical basis and enough practical activity. Unfortunately, competence skills in the field of modern analytical methods are insufficient. At the same time, modern chemistry has become more "physical" even in classical synthetic fields such as organic chemistry. So the knowledge of instrumental methods of analysis is highly demanded. We are trying to fill this gap by additional lessons on NMR, MS, UV-Vis spectrometry and other modern techniques. However, we have the lack of equipment 
to run the discussed methods on the regular basis. The school digital labs with analytical sensors allow performing some quantitative experiments, but cannot replace a well-equipped laboratory as was mentioned above. Thus, an ideal solution is to encourage students to research under supervising in scientific labs.

Another problem we faced was the motivation of researchers to collaborate. Usually the majority of scientific experience is obtained according to "follow me" principle, so the initial learning may be very prolonged. At school, students usually do not have enough free time. There are several ways to overcome this problem. The obvious approach is a summer schools or special experimental labs for students, such as XLAB [3], where students can learn common experimental methods and techniques and perform some experiments for their own investigations. Another very good opportunity appears if school teachers are able to show to students how to make at least first steps of research. However, the majority of school teachers both in Russia and other World have no scientific experience. Therefore, common scientific education for teachers is strictly required for successful interaction between school and science [4].

\section{Bioinformatics study example}

One of representative examples of high school level investigations are AESC students projects in bioinformatics. Bioinformatics is closely related with a number of regular school courses such as geometry, chemistry, biology and informatics. In spite of its novelty, some of research works in this interdisciplinary field of science available to high school students with basic educational skills. These projects were started from the beginning of life science class. At the time this field of science allows to perform modern science level projects "at home", using only computers and Internet without direct collaborations with research groups. Modern scientific equipment and reagents are not necessary also in this case. To support this attempt, special courses of informatics and protein chemistry were developed.

As typical case we try to identify different motifs in protein 3D structure. Structures of proteins can be taken from PDB database [5]. Comparing of structures is performed with free visualization software: SwissPDBViewer or PyMOL [6]. Usually, as subject of investigation we choose antibody structures. This subject has advantages of hundreds of available spatial structures and developed theory for further structure modeling. Improving of this theory on the base of comparison of available structures appeared a fruitful field for high school projects.
Different aspects of antibody structure organization were studied. For instance, might be mentioned study of antibody CDR H3 conformation [7], consideration of small aromatic molecules binding [8] or negative charged ligand binding [9]. These publications have high citation index that proved a possibility of reaching of frontier of modern science in the high school projects. Later studies in this field were greatly supported by FBB MSU and now a lot of current projects in bioinformatics are performing under supervision of FBB researchers also.

\section{Conclusion}

The project activity allows our students to get an experience of work on modern scientific researches [10]. They learn how to discuss, formulate and present results of studies and establish initial social links in scientific community. The most important result is that they understand the process of new knowledge discovering. It results in increase of their publication activity at undergraduate level in comparison with other students [11]. Nevertheless, project-based approach can be efficient only when it is supported both from school and from scientists.

We have showed that project-based approach in addition to ubiquitous education allows us to reach fruitful collaboration between school and scientists. Our students successfully take part in serious scientific investigations and obtain valuable results.

\section{Acknowledgements}

We thank to AESC MSU development program by the Ministry of Education and Science of Russia for financial support. Also we thank STEM-centre program (http://stemcentre.ru).

\section{References}

[1] E.-M. Neher, (2006) 'XLAB-Goettingen Experimental Laboratory for the Youth Bridging the Gap Between High School and University', NATO Security through Science Series - E: Human and Societal Dynamics, IOS Press, 16, pp. 111-117.

[2] AESC web-site (Russian only), http://internat.msu.ru/ (16 December 2015). Chemistry chair web site (English), http://internat.msu.ru/structure/chairs/kafedrahimii/chemist ry-chair/ (18 December 2015)

[3] C. Goodman, (2009) 'From students to scientists at XLAB', Nat Chem Biol, Nature Publishing Group, 5, p. 194.

[4] P. Velek and À. Gras-Velázquez, (2014) 'Online Teacher Training in European Science Education Projects', EDULEARN14 Proceedings, Barcelona, Spain, p. 6622. 
[5] Protein Data Bank, http://www.rcsb.org (16 December 2015).

[6] SwissPDBViewer web site http://spdbv.vital-it.ch/ (18 December 2015) PyMOL web site http://www.pymol.org/ (18 December 2015)

[7] O. Koliasnikov, M. Kiral, V. Grigorenko, A. Egorov, (2006) 'Antibody CDR H3 modeling rules: extension for the case of absence of Arg H94 and Asp H101', Journal of bioinformatics and computational biology, 4(02), p. 415424.

[8] V. Arzhanik, D. Svistunova, O. Koliasnikov, A Egorov, (2010) 'Interaction of antibodies with aromatic ligands: the role of $\pi$-stacking', Journal of bioinformatics and computational biology, 8(03), p. 471-483.

[9] A. Petrov, V. Arzhanik, O. Koliasnikov, (2015) 'A novel conservative binding motif in antibodies: a correlation between sequence and binding properties of immunoglobulins', Proceedings of 7th Moscow Conference on Computational Molecular Biology, July 1619, 2015, Moscow, Russia. IITP RAS, Moscow, Russia.

[10] 'List of creative research projects of AESC students', Division of chemistry of AESC MSU (Russian mostly), http://internat.msu.ru/structure/chairs/kafedrahimii/tvorche skie-issledovatelskie-raboty-po-himii/ (16 December 2015).

[11] O. Koliasnikov, E. Mendeleeva, A. Sigeev, M. Sergeeva, N. Morozova, (2015) 'Project-based learning as a way to cover the gap between school curriculum and contemporary chemistry' Proceedings of 45th World Chemistry Congress. BEXCO, Busan, Korea. August 9-14, 2015. Busan, Korea. 